\title{
Fitotopónimos y sinfitotopónimos del poniente granadino
}

\section{Phytotoponymy and Synphytotoponymy in Western Granada Province (Andalusia, Spain)}

\author{
Guillermo Benítez Cruz, M. Reyes González-Tejero \\ y Joaquín Molero Mesa \\ Departamento de Botánica. Facultad de Farmacia. \\ Universidad de Granada
}

\section{RESUMEN}

En el marco de la investigación etnobotánica desarrollada en el poniente granadino, se ha realizado un estudio sobre la toponimia de la comarca con atención a los apelativos de origen vegetal (fitotopónimos y sinfitotopónimos). La información -obtenida de la Gerencia Territorial del Catastro de Granada, de la Junta de Andalucía y de nuestro trabajo de campo- se ha incluido en una base de datos con el programa Microsoft Excell®. Un total de 98 especies vegetales se encuentran representadas en la toponimia local, dando nombre a 593 lugares del territorio. Se aportan comentarios sobre el significado ecológico, paleofitogeográfico y etnobotánico de las especies reflejadas en la toponimia.

Palabras clave: Fitotoponimia, Fitotopónimos, Sinfitotopónimos, Granada, Andalucía, Paleofitogeografía, Etnobotánica.

\section{SUMMARY}

Within the framework of a research project on the ethnobotany of the western section of the province of Granada, in southern Spain, a detailed study was made of place names derived from names related to plants (phytotoponyms and synphytotoponyms). The information - gathered from the Territorial Land Registry of Granada, the Regional Government of Andalusia and field work - has been included in a database written with the Microsoft Excel program. References to a total of 98 plant species were found in as many as 593 place names of the area. The authors comment on the environmental, paleophytogeographic and ethnobotanical significance of the species represented in the place names.

Key words: Phytotoponymy, Phytotoponyms, Synphytotoponyms, Province of Granada, Andalusia, Spain, Paleophytogeography, Ethnobotany. 


\section{INTRODUCCIÓN}

La toponimia analiza los nombres vernáculos que la población de un territorio da a un lugar determinado. Distintos autores han tratado en diversos territorios del Estado los topónimos derivados de nombres de plantas, generalmente formando parte de estudios de toponimia a nivel más general. Principalmente ha ocurrido por parte de filólogos, geógrafos o historiadores, estudiosos de los topónimos, subrayando sobre todo aquellos términos que derivan de lenguas habladas antiguamente en territorio peninsular como el latín, el árabe o el celtíbero. Sin embargo son pocos los trabajos específicos sobre fitonimia (Torres 2004).

El concepto de topónimo es dinámico, ya que son empleados principalmente por la población local, que contribuye a su delimitación y nomenclatura, dando y modificando nombres de lugares con el paso del tiempo. Sin embargo, estos nombres pueden ser interpretados como fósiles ya que, normalmente, no han evolucionado desde muy antiguo; de esta manera, los topónimos ofrecen una información muy valiosa tanto sobre el medio físico y biológico, como sobre otros aspectos étnicos, sociales o culturales, de los pueblos que moraban el territorio (Llorente Maldonado 1991). Estamos de acuerdo con Sanz Elorza y González (2006) y Villar (2003) en que esos nombres constituyen un importante acervo cultural, de cuyo análisis se puede sustraer valiosa información del medio y de sus antiguos pobladores. En palabras de Julio Caro Baroja (1991): "La toponimia es un elemento de conocimiento de la antropología y de la etnología, fundamental para tener una imagen del medio según pobladores de distintas épocas y de distinto origen”.

La clasificación de los topónimos es diversa: macrotopónimos alusivos a territorios geográficos de amplia extensión y microtopónimos para los parajes locales, nombres de accidentes geográficos pequeños, ríos, montes, etc. En función del tipo de accidente geográfico a que da nombre se consideran entre otros, hidrónimos (aluden a ríos y arroyos), orónimos (nombran una cordillera, montaña o elevación del terreno), agrotopónimos (si son referentes a paisajes agrarios), etc. En relación a su origen, destacan los antropónimos, procedentes de nombres de personas o familias, los zoónimos, de nombre de animales y los que aquí nos ocupan, los fitotopónimos o fitónimos (ambos términos admitidos por la RAE) derivados de nombres de vegetales.

Un caso particular, cuya formación ya ha sido analizada por Ruiz de la Torre (1998) es el de los sinfitónimos, definidos como "sustantivos o eventualmente adjetivos que designan una colectividad vegetal o conjunto de vegetales, semejantes o diferentes que conviven en una extensión de terre- 
no". Villar (2005) ha analizado aquellos relativos al Alto Aragón obteniendo resultados interesantes: en esta comarca las derivaciones de los nombres vernáculos de unos 40 arbustos han producido aproximadamente unos 700 sinfitónimos o fitónimos plurales.

Precisamente las relaciones existentes entre la población y cultura de un lugar y su medio ambiente es el objeto de estudio de la etnobiología, que analiza cómo el ser humano se relaciona, trasforma, obtiene recursos, etc. de su medio, pudiendo definirse como "el estudio del saber popular en materia de historia natural" (Barrau 1976). Dentro de ella, la etnobotánica se interesa por las relaciones entre un núcleo cultural determinado y los vegetales de su entorno, cultivados o silvestres, con los que se alimenta, viste, calienta, cura, alimenta sus animales, construye, etc. La línea de investigación sobre etnobotánica que seguimos en el Departamento de Botánica de la Universidad de Granada con varios años de trabajo en este territorio motivó la realización de este estudio y facilitó diversos aspectos metodológicos.

\section{Metodología}

El trabajo comprende el estudio de los topónimos de 16 municipios, comprendidos en el Consorcio del Poniente Granadino: Algarinejo, Alhama de Granada, Arenas del Rey, Cacín, Huétor Tájar, Íllora, Jayena, Loja, Moclín, Montefrío, Moraleda de Zafayona, Salar, Santa Cruz del Comercio, Villanueva del Mesías, Zafarraya y Zagra. Entre ellos ocupan una superficie de 2.042 $\mathrm{Km}^{2}$ (algo más del $16 \%$ de la superficie de la provincia de Granada).

Se han analizado dos bases de datos de topónimos, una de la Junta de Andalucía publicada por el Instituto de Cartografía (1990) y otra, más extensa, relativa a los topónimos de parajes, de la Gerencia Territorial del Catastro de Granada. Se han catalogado para el territorio 1.209 entradas en la primera base de datos y 3.668 en la segunda. En ocasiones se han encontrado dos nombres muy similares que aluden a un mismo lugar, por ejemplo San José y Ventorros de San José, en Loja, en cuyo caso se han eliminado las repeticiones, ascendiendo el número final de registros a 4.470 .

Se seleccionaron los topónimos que derivan directamente de nombre de plantas conocidos (llamados topónimos transparentes), tanto en singular (fitónimos singulares: almendro, encina), como en plural (fitónimos plurales: almendros, alazores) y los que son nombrados por formaciones vegetales (sinfitónimos: encinar, espinar, zarzal). Por otro lado, se indagó en la bibliografía especializada sobre toponimia para buscar aquellos que, derivando de otras lenguas (particularmente en este territorio de origen árabe o latino), procedan de nombres de plantas o formaciones vegetales en dicha lengua (fitónimos opacos), basándonos principalmente en los trabajos 
de Asín (1944), Seco de Lucena (1974), Martínez (2002) y Calvo (1990), cuya inclusión siempre va acompañada de la fuente correspondiente. Por último, incluimos topónimos dudosos que, a priori, podrían ser alusivos de nombres vernáculos de plantas que no estuvieran catalogados aún, para cotejarlos posteriormente en el trabajo de campo. Algunos localismos referentes a plantas ya fueron registrados en los trabajos sobre el habla y vocabularios de zonas muy cercanas (Rodríguez 1996; Fernández 1982; Galeote 1988).

Con los topónimos incluidos en la lista preliminar realizamos un trabajo de campo para comprobar datos, indagando en las localidades sobre el topónimo, su ubicación y procedencia, partiendo siempre del saber popular del territorio. En muchos casos se ha preguntado si se conoce alguna planta llamada de un modo concreto, o si podrían saber qué tipo de paisaje vegetal existiría en ese emplazamiento con anterioridad.

La metodología empleada en el trabajo de campo es la utilizada habitualmente en los estudios de etnobotánica cualitativa (Cotton 1996; Martin 2004), seleccionando informantes locales, en general de edad avanzada, buenos conocedores del entorno, sus plantas y vegetación. En muchos casos se ha recurrido a los mismos informantes que nos ayudaron en el trabajo que estamos llevando a cabo sobre la etnobotánica del Poniente Granadino. Hemos realizado entrevistas abiertas y semiestructuradas y, en bastantes ocasiones, salidas al campo para buscar la especie referida localmente en la toponimia cuando existían dudas. Este es el caso, por ejemplo, de varios topónimos con la palabra espino, vocablo por el que normalmente se designa en la zona a Crataegus monogyna Jacq., si bien existen hasta 6 especies espinosas denominadas genéricamente espino, añadiendo un epíteto específico (espino prieto a Rhamnus lycioides L. y Rhamnus myrtifolius Willk., espino negro a Prunus spinosa L. y Rhamnus saxatilis Jacq., espino real o espino arro a Berberis hispanica Boiss. \& Reut., espino cambrón a Lycium europaeum L.).

La selección de informantes y la visita a ciertos lugares con topónimos dudosos se vio favorecida por el trabajo etnobotánico que, como ya hemos comentado, venimos desarrollando en esta comarca (Benítez 2007, 2009) y que ha hecho que tengamos un detallado conocimiento del territorio. De otra parte, el trabajo de González-Tejero (1989) sobre la provincia de Granada nos ayudó en gran manera al análisis de los nombres de plantas empleados generalmente por los granadinos.

Para contrastar los nombres de las plantas a nivel más general y algunos nombres de vernáculos en desuso en esta zona, pero reflejados en la toponimia, se han empleado fuentes botánicas especializadas (Ceballos 1998; Morales et al. 1996), así como diversos diccionarios (RAE 1995; Moliner 1983; Corominas y Pascual 1980-1987). Los datos se incluyeron en una base de 
datos de Microsoft Excell y se han analizado estadísticamente con posterioridad.

En este trabajo se han seleccionado únicamente los topónimos que derivan del reino vegetal, nombrados por una planta o formación vegetal, dejando a un lado para futuros análisis los que sean alusivos al paisaje (por ejemplo "llano de...", "torcal...", "secano", "umbría", "huerta de...", "salar", etc.) o al manejo de los vegetales por el hombre (como "horno de...", "melera", "barranco carboneros", "especiero", etc.). No obstante se han incluido también aquéllos cuyo nombre está directamente relacionado con alguna planta, aunque no sea la planta la que nombre el lugar. Es el caso de las "dehesas", que, además de indicar un modo de manejo del medio, aluden prácticamente siempre en este territorio a Quercus rotundifolia Lam.; "sarmiento" relativo siempre a Vitis vinifera L. o "la resinera", nombrada por el pino resinero, Pinus pinaster Aiton, entre otros.

\section{RESULTADOS}

Se han obtenido 593 fitotopónimos y sinfitotopónimos de un total de 4470 catalogados, lo que corresponde a un 13,26 \% de los topónimos registrados para el Poniente Granadino.

Dichos topónimos son alusivos a 98 taxones vegetales. En doce ocasiones sólo consideramos oportuno acercarnos hasta el nivel de género, el resto hasta nivel de especie. La relación de géneros y especies, sus nombres vernáculos locales registrados y los topónimos que nombran junto con el municipio donde se encuadran, están representados en la tabla 1.

De ellos, destacan por su repetición plantas como la vid (Vitis vinifera, con 52 topónimos), los chopos (Populus sp., 35), el moral (Morus nigra L., 31), el olivo (Olea europaea L., 27), los pinos (Pinus sp., 26 contando los topónimos que se han llevado a Pinus pinaster Aiton y Pinus pinea L.), el espino (Crataegus monogyna Jacq., 19), las zarzas (Rubus ulmifolius Schott., 18), el peral (Pyrus communis L., 17), las rosas (Rosa sp., 15), el quejigo (Quercus faginea Lam., 14), la higuera (Ficus carica L., 14), el almendro (Prunus dulcis (Mill.) D. A. Webb, 14), o los sauces (Salix sp., 12), además del principal formador del paisaje vegetal natural en este territorio, el chaparro o encina (Quercus rotundifolia Lam., con 44 topónimos).

Un total de 240 corresponden a sinfitotopónimos (40.5\%), designando distintos tipos de comunidades tales como agrazal (abreviatura de agracejal, comunidad de agracejos, Berberis hispanica Boiss. \& Reut.), alcornocal, almendral, abulagares (localismo de aulagares, Ulex parviflorus Pourret), cardeal (comunidad de cardos, normalmente Eryngium campestre L.), cornicabral, alamedilla, dehesa, chaparral, endrinal (comunidad de endrinos, Prunus 
spinosa L.), nebrales (derivado de enebrales, comunidad de enebros (Juniperus oxycedrus L.), altochar (sinónimo de espartal, Stipa tenacissima L.), esparragales, espinar, fresneda, guindalera, higueral, jaral, estepar, juncal, madroñal, membrillar, moraleda, naranjal, olivar, pereda (varios perales juntos), pinar, quejigal, retamar, romeral, sauceda, tejeda, tomillar, parrizales, zumacal, etc.

En total aparecen 42 familias vegetales en la formación de topónimos en el Poniente Granadino. Las familias con más taxones representados en la toponimia de este territorio son: Rosaceae: 14, Asteraceae: 9, Poaceae: 6, Fagaceae: 6, Fabaceae: 6, Lamiaceae: 4.

De las especies incluidas, aproximadamente un $62 \%$ (61 de 98) corresponde a especies que aparecen de forma natural o están naturalizadas en el territorio (como la caña), mientras que el $38 \%$ necesitan ser cultivadas, pese a que algunas tienen en el territorio formas silvestres (como el olivo). Esto denota un papel muy importante en la toponimia local de los vegetales que se han cultivado de forma histórica, algunos de los cuales se han abandonado en la actualidad.

Destaca la presencia de muchos árboles frutales (naranjo, limonero, granado), principalmente de la familia rosáceas (almendro, cerezo, ciruelo, melocotonero, guindo, manzano, membrillo, peral, serval), y especies hortícolas como la alcachofa, el rábano, nabo, calabaza, melón, haba, yero, azafrán, cebolla, así como cereales: centeno, trigo, escañuela y otras textiles, como el lino o el cáñamo.

Un total de 5 topónimos incluidos son opacos, y proceden de lenguas antiguas de este territorio (latín o árabe), cuya inclusión como alusivas a una especie determinada se debe a la revisión de las fuentes anteriormente citadas. El topónimo "Barranco de Albuñuelas" de Jayena, así como el pueblo granadino del mismo nombre, derivan de la forma árabe al-bunyu:l, que significa "tierra de viñas" (Asín 1944). Los "Talancos" de Villanueva deben su nombre a la deformación de la forma árabe harat al-anqud, que significa "barrio de la vid" (Martínez 2002). La forma "Marrojas" para designar el marrubio procede al parecer del nombre mozárabe de la planta, marruwaš, singular marruyu, derivado del latín Marrubium (Asín en Martínez 2002). El caso del topónimo "Palopar", o el del nombre de Polopos, pueblo de Granada, parecen derivar de la forma mozárabe polopar, que se refiere al plural colectivo de la forma latina Populus (Martínez 2002). Por último, la evolución del nombre "Frontil" se basa en la eliminación de la primera palabra que formaba el topónimo árabe qaryat al-funtin, que significa "fuente del higo" (Seco de Lucena 1974). 


\section{DISCUSIÓN}

La deducción de los fitotopónimos se ha realizado, en general, conociendo previamente los nombres vernáculos de las especies, gracias a la bibliografía botánica y etnobotánica y a nuestros trabajos previos en la zona. Sin embargo, en alguna ocasión el proceso de deducción fue inverso: a partir de un topónimo sin identificar, denominado con un término que a priori podría ser un nombre local de alguna planta, se indagó durante el trabajo de campo y nos indicaron alguna planta denominada con ese nombre vernáculo, acudiendo posteriormente al campo para comprobar el taxón. Este es el caso de "El Escopatar" en Jayena, donde dan el nombre de escopata a Genista spartioides Spach. El topónimo "El Mostazo", a priori alusivo a algún jaramago del género Sinapis L., ha sido asociado a la especie Sorbus aria L. tras conversaciones con personas de la zona, ya que éste es su apelativo popular en todos los pueblos de la Sierra Tejeda y Almijara, aunque, comúnmente, sea llamado mostajo en otros territorios. De igual modo incluimos los topónimos que contienen "brazal", tras averiguar que la palabra es empleada por los lugareños para designar los zarzales (comunidades arbustivas espinosas ligadas al agua, con presencia de Rubus ulmifolius Schott.).

Por el contrario, en base al trabajo de campo hemos excluido de la lista de topónimos nombres que, en principio, parecían alusivos a plantas, pero que fueron relacionados en las entrevistas con denominaciones de personas (antropónimos) o animales (zoónimos). Es el caso del "Cortijo del Pericón" (Zafarraya), derivado de Pedro, nombre de un antiguo propietario y no derivado de hipericón, de "Cortijo Chichilla" (debe su nombre a las chinches), "Cortijo de la Mirra" (en el territorio no conocen por este nombre a ninguna planta aromática sino a un ave paseriforme), etc. Caso particular es el de "Cortijo Golleto" en Íllora, que parece derivar según los informantes de una raza de pollos llamados "golletos" que tenían el cuello pelado por detrás. Sin embargo, en las zonas de vega muchos agricultores llaman "golletina" a Chenopodium ambrosioides L., de donde podría derivar, de forma quizás menos probable. Cabe cierta duda en aquellos coincidentes como fitónimo o antropónimo, derivados de apellidos con nombres de plantas como por ejemplo Morales, Oliveira, Zamora, Castañeda o Narciso, en cuyo caso no podemos saber con certeza su origen derivado de la existencia pretérita de estos vegetales en el territorio.

También en base a las entrevistas se han eliminado del listado final algunos topónimos que podrían derivar de denominaciones locales de algunos vegetales. Estos son: "Arroyo y Barranco de Tora" en Montefrío y "Ba- 
rranco de Pimentela" en Algarinejo (con esos nombres se conoce a varias plantas en otras zonas peninsulares, pero a ninguna en nuestra comarca hasta donde sabemos), "Las Cabezuelas" en Santa Cruz (se conoce por "cabecicas" a Anchusa azurea Mill., pero la población local duda de este origen para el topónimo), "Las Amargueras" en la misma localidad (se conoce por "amargosa" a Mantisalca salmantica, caso similar al anterior), "Jabonero" y "Huerta del Jabonero" en Alhama (derivado del apodo de un antiguo propietario del terreno, no de la planta Saponaria officinalis L.), así como varios que contienen la palabra "amarguillo", posiblemente derivados de algún vegetal cuyo nombre cayó en el olvido (en otras zonas se conoce de formas similares a distintas especies de Teucrium). Al menos en los casos de "tora" y "pimentela", y posiblemente también de "amarguillo", al presumir que proceden de nombres de vegetales cuyo conocimiento se ha perdido o queda muy oculto en la cultura local, podríamos hablar de una erosión lingüística, suponiendo que se hubiera perdido el significado local de estas palabras.

No se han incluido en este estudio algunos microtopónimos de los que hemos tenido constancia durante el trabajo de campo, que no están recogidos en ninguna de las bases de datos analizadas, bien por su empleo local, o porque designan parajes pequeños no representados en las cartografías. No obstante, son interesantes los casos de la "Cuesta del Rascal" en Jayena, alusivo al rasca o rascaviejas, Adenocarpus decorticans Boiss., especie calcífuga cuya representación en la toponimia indica un afloramiento esquistoso en una zona donde el sustrato predominante es calco-dolomítico, o del "Cerro de las Macucas" de Zafarraya, nombrado por Bunium macuca Boiss., especie muy apreciada y recolectada como alimenticia en épocas de escasez en todo el Poniente Granadino.

\section{Interpretación ecológica}

Respecto al significado ecológico de estos topónimos es destacable que las principales especies formadoras del paisaje en el territorio quedan recogidas en su nomenclatura, como muestra de su importancia como referencia geográfica. Aparecen en numerosas ocasiones lugares nombrados por la encina, como por ejemplo, "Encinillas" en Loja o "Chaparrilla" en Moclín, así como por su colectivo plural: "Dehesilla" en Huétor Tájar, "Carrascal" en Zafarraya, etc. También están representadas en la toponimia distintas etapas de sustitución del encinar sobre sustratos básicos (la mayor parte del territorio es calcáreo), como los retamales ("Majada de retameros" en Alhama o "El Retamal" en Moclín) y otros arbustos retamoides ("El Escopatar" en Jayena), los jarales ("El Jaral" en Alhama y Montefrío, "Estepar" en Montefrío), 
los romerales y tomillares ("El Tomillar" en Moclin, "El Romeral" en Alhama e Íllora), salviales ("Loma del sabial" de Cacín), aulagares ("Abulagar" en Jayena), espartales ("Espartal" en Salar o "El Altochar" en Loja), así como otras especies del matorral ruderal como artemisias ("Sancarrañal" en íllora) o marrubio ("Arroyo las Marrojas" de Algarinejo). Especies de terrenos alterados o nitrificados quedan identificadas también en la toponimia, como los gamones de lugares pedregosos de las sierras ("Gamonital" en Algarinejo), las cerrajas ("Cerrajón" en Loja) y los distintos tipos de cardos espinosos ("El Garranchal" en Íllora, "La Toba" en Loja, "El Cardeal" en Arenas del Rey o "Tagarninas" en Loja).

Otras plantas importantes por su significado ecológico son las que forman la orla espinosa de bosque, como el espino majoleto, majuelo o simplemente espino ("Majuelo" en Íllora, "Espino" en Loja y Montefrío, una de las plantas con más nombres vernáculos del territorio), el endrino ("Endrinal" de Montefrío), los rosales silvestres ("Barranco del rosal" en Algarinejo, "La Rosa" en Arenas del Rey, etc.) e incluso el agracejo ("El Agrasal" de Algarinejo).

En los lugares de sustratos calcáreos más frescos y profundos, el encinar deja paso a un quejigal, cada vez más devastado por la transformación del suelo en cultivos, cuya mayor abundancia pretérita queda de manifiesto en la cantidad de topónimos en los que interviene, por ejemplo "Los Quejigales" en Loja, el "Barranco del Quejigal" de Montefrío o "Los Quejiguillos" en Arenas del Rey. En muchos de estos lugares el único árbol presente actualmente es el olivo.

Escaso en la actualidad pero seguramente mucho mas abundante en el pasado, el tejo (Taxus baccata L.) nombra el macrotopónimo de "Sierra de Tejeda”, límite natural entre las provincias de Málaga y Granada. También aparece en otros topónimos menores como "Barranco de los tejos" en Alhama. Sin embargo, existen varios topónimos alusivos a "tejar", que no son fitónimos sino que aluden a lugares de donde se sacaba el barro o arcilla para la elaboración de tejas, y otros "tejones", que habría que asociar al tejón, constituyendo entonces un zootopónimo.

Podemos saber que están sobre sustratos ácidos los lugares nombrados por especies acidófilas como el alcornoque ("Alcornoque" en Alhama, "Sierra del Alcornocal" en Algarinejo), el roble o roble melojo ("El Robledal" en Alhama en la base de $S^{\underline{a}}$ Tejeda), o el castaño ("Castañeda" en Loja, en cuyo caso bien podría proceder del apellido Castañeda, relativamente frecuente en Loja y no de una formación de castaños, duda que no hemos podido resolver).

Hay fitotopónimos que indican cierta termicidad en el clima general del territorio, como el "Cortijo del Lentisco" de Loja, el pueblo de "Limones" en 
Moclín, o los referentes a las palmas, vocablo con el que se nombra de forma general a las palmeras (Phoenix dactylifera L. o Ph. canariensis Hort. ex Chab.). También los hay que incluso indican cierta sequedad ombrotípica, como la "Loma de las coscojas" de Arenas del Rey, pues, como es sabido, los requerimientos hídricos de esta quercínea son menores a los de la encina, principal árbol forestal de este territorio.

Las formaciones vegetales ligadas a cursos de agua aparecen igualmente bien representadas en la toponimia. En mayor número aparecen topónimos referentes a los chopos, bien de forma directa como "El Chopo", existente en tres municipios: Alhama, Algarinejo y Loja, o "Los Álamos" de Montefrío (plural colectivo), así como por su formación vegetal, las choperas o alamedas: "Alamedillas" en Íllora. También hay muchos asociados a las saucedas, derivados mediante distintos sufijos como "Salcedo" en Alhama, el "Barranco Saucedilla" en Algarinejo o "La Mimbre" en Jayena.

Los cañaverales, carrizales y juncales quedan identificados en el territorio en lugares como "Barranco de las Cañas" en Arenas, "Cañaílla" en íllora, "Cortijo del Carrizal" en Algarinejo, "Solana del Carrizal" en Montefrío, "Cortijo Juncos" en Alhama, "Arroyo del Juncar" en Salar, etc. (de forma general se conoce por junco a Scirpoides holoschoenus (L.) Sojak, no a ninguna especie del género Juncus L.). El fresno (Fraxinus angustifolia Vahl.) aparece reflejado como fitotopónimo singular y como sinfitotopónimo, como por ejemplo en "Arroyo del Fresno" y "Cortijo de la Fresneda" en Loja y Montefrío. Los zarzales, indicadores de suelos profundos y húmedos en el dominio de las olmedas y choperas, quedan patentes en nombres de lugar como "La Zarzuela" en Algarinejo, "Barranco Zarzas" en Arenas o "Barranco Zarpadilla" en Moclín, además de lo mencionado en el caso de "Brazal", apelativo popular de zarzal.

En cuanto a los topónimos opacos derivados del árabe, estudiados en la bibliografía, la complejidad en su interpretación puede dar lugar a diversas hipótesis. Así por ejemplo, el origen del macrotopónimo "Almijara" tiene varias teorías. En algún caso se cree derivado del árabe ašara, "plantío de árboles”, como en el topónimo Almáxara de Castellón (Calvo 1990; Martínez 2002). En otras ocasiones se relaciona con la voz majar, por lo que almijara significaría "lugar de prados", de forma similar al topónimo Almarjal en Alicante (Calvo 1990). Sin embargo, la definición del vocablo en el diccionario es: "depósito de aceite que había en las minas de almadén para repartirlo a los operarios para el alumbrado" (Moliner 1983), derivado de Almijar, acepción recogida para Andalucía como: "lugar donde se ponen a secar las aceitunas o las uvas antes de exprimirlas. Lugar donde se ponían a secar los higos" (Moliner 1983). Por tanto, no podemos saber ciertamente a qué especie vegetal debe su nombre esta sierra dolomítica. 


\section{Interpretación paleofitogeográfica; análisis de ciertas especies}

Como ya pusieron de manifiesto Sanz Elorza y González (2006), el estudio de la toponimia de origen vegetal tiene un importante valor para los estudios etnobotánicos, ya que refleja las especies y manejos del paisaje más importantes para la población y cultura local, de igual modo que para los estudios paleofitogeográficos. En este último sentido otros autores (Salas y Cáceres 2000) han analizado fitotopónimos determinados con intención de aportar pruebas sobre la presencia pasada de especies consideradas actualmente alóctonas de un territorio.

En el caso de la paleofitogeografía del Poniente Granadino y en relación a la fitonimia, es interesante el empleo de especies cultivadas anteriormente en la zona para designar lugares de vega, permaneciendo actualmente sus topónimos, pese a que su cultivo ha quedado abandonado. Es el caso del cáñamo o del lino ("Cañamero" en Algarinejo o "Linarejo" en Arenas del Rey y "Cortijo de los Linarejos" en Montefrío). Otro posible ejemplo es el "Puerto de los Alazores" en Zafarraya, probablemente alusivo a una especie cultivada como tintórea y condimentaria en época musulmana (Carthamus tinctorius L.), que parece no estar presente actualmente en ese territorio, si bien podría corresponder con un zootopónimo derivado del azor, ave rapaz. Mención especial merece la gran cantidad de topónimos alusivos al moral (Morus nigra L.), especie abundantemente cultivada en todo el Reino de Granada como sustento de la industria de la seda, cuya decadencia a partir del siglo XV ha quedado muy documentada (cf. Morell y Ferry, 1888). La morera, Morus alba L., de requerimientos ecológicos más térmicos, queda bastante menos reflejada que su congénere debido a las condiciones climáticas del territorio.

Respecto a especies silvestres llama la atención la presencia de un "Camino de Abellanos" en Íllora, especie acompañante del quejigal, bastante escasa en las Sierras Béticas. En la actualidad, la especie no existe en esa localidad, pero su presencia pretérita es más que probable. Debe tratarse de un topónimo bastante antiguo, pues además de haberse mantenido escrita con b como en los textos antiguos, se trata de una zona (próxima al núcleo de Escóznar en Íllora) muy antropizada y ocupada prácticamente por el cultivo del olivo, pero probablemente cubierta de bosques caducifolios hasta el siglo XVIII, por estar muy próxima al conocido "Soto de Roma".

Un dato curioso es el del topónimo encontrado en un documento del Archivo Histórico de Loja (legajo 68, documento 5, de título: "Autos fechos en virtud de carta de instrucción del Consejo sobre el plantio de los montes $i$ conservación dellos y acoto de tierras para que se crien, año de 1625"), deno- 
minado "Hornillo de la Miera", en la vertiente norte de la Sierra de Loja. Del topónimo se deduce que debía existir una población abundante de enebros de la miera (Juniperus oxycedrus) en ese territorio (ya que existió un horno para la extracción de miera). En la actualidad, posiblemente debido al manejo que se hizo de esta especie, no se encuentra ningún individuo en esta sierra (hecho constatado, ya que no está presente en el catálogo florístico existente, cf. Marín 1978) y sin embargo sí está presente en las sierras colindantes, como el Hacho o la Sierra de Gibalto.

En Montefrío, concretamente en la Sierra de Parapanda, aparece el topónimo "El Endrinal" o "Los Endrinales" (Prunus spinosa). Es curioso este hecho, ya que esta especie alcanza prácticamente en este territorio su límite meridional en Andalucía Oriental, siendo sustituida en Sierra Nevada y aledaños por Prunus ramburii Boiss. La población actual es bastante escasa en individuos, pero del topónimo se deduce que es una especie apreciada en la cultura local, lo que hemos podido comprobar, además de responder a ciertos usos populares. Todo ello nos indica que debió ser más frecuente en tiempos pasados.

El madroño, Arbutus unedo L., aparece en tres topónimos de Arenas, Íllora y Moclín, y actualmente no es una especie frecuente en esta zona, ni siquiera muy empleada por la población, aunque bien conocida por lo general. Por su ecología, acompañante en encinares, alcornocales y formando parte de los matorrales de su degradación, posiblemente fuera más frecuente en tiempos pasados, cuando estos ecosistemas estuvieran mejor conservados.

Por último, debemos señalar en este apartado tres especies ya mencionadas, tan escasas en la actualidad que han sido incluidas en el Catálogo Andaluz de Especies Silvestres Amenazadas (Decreto 104/1994, B.O.J.A. 14/ VII/1994), cuya extensión probablemente fue mayor, y que han prestado sus nombres para la designación de algunos lugares. Por un lado, el avellano, especie montana de lugares frescos y húmedos acompañante del mermado quejigal y muy escaso en la provincia, protegido en Andalucía con categoría "vulnerable". Por otro lado, el tejo, catalogada en Andalucía como "en peligro de extinción" da nombre a 2 lugares, uno de ellos la "Sierra de Tejeda”, nombrada así por la abundancia pasada de este árbol (Laza 1947), que no pudo ser constatada por los botánicos que la visitaron a partir del siglo XIX: Boissier (1839-1845) o el mismo Laza Palacios (1947) ya hicieron sendas alusiones a su escasez. También presente en el Catálogo Andaluz como "vulnerable", Sorbus aria (L.) Krantz, nombrado comúnmente mostajo, pero llamado en la zona por derivación fonética mostazo, da nombre al lugar conocido como "el mostazo", en la Sierra de Tejeda (municipio de Alhama), donde no es rara. 


\section{Interpretación etnobotánica}

El $89.8 \%$ de las especies silvestres (88 en total) que aparecen en la toponimia tienen un empleo en la etnobotánica local (Benítez 2007, 2009; González-Tejero 1989 y datos propios) o se emplean de forma más generalizada, como las cultivadas. Esto revela que al nombrar los lugares se ha pretendido emplear siempre referentes bien conocidos por la población, en el caso de plantas, especies importantes para cada cultura por su nivel de utilización, o elementos relevantes en la formación del paisaje. Entre las especies con uso en la toponimia del territorio existen algunas que no tienen empleos populares en la actualidad, sin embargo, algunas de ellas tuvieron en el pasado un uso evidente. Un ejemplo podría ser el espino cambrón (Lycium europaeum), al que todavía se ve en hileras delimitando antiguas lindes de fincas, empleo que nadie parece recordar en este territorio.

Respecto a la etnotaxonomía local de las especies más emblemáticas o conocidas, podemos destacar que la diversidad de vocablos para designarlas es alto, existiendo por lo general más de dos nombres o derivaciones fonéticas de la misma palabra para designar un taxón vegetal. Esta sinonimia vernácula queda patente en especies como Crataegus monogyna, denominado espino, espino majoleto, majoleto, majuelo o espino blanco prin-

cipalmente, o Marrubium vulgare L., llamado por lo general marrubio, o también matroncho. Por el contrario, también se dan casos de polisemia, utilizando el mismo nombre para varios taxones vegetales. Además del caso ya comentado sobre los espinos (hasta 7 taxones diferentes), por retama no solo se conoce a Retama sphaerocarpa (L.) Boiss., aunque sea la más frecuente, sino también puntualmente a Genista cinerea (Vill.) DC., Spartium junceum L. (normalmente llamado gayomba o en algún caso retama macho) e incluso a Cytisus scoparius (L.) Link. Son aspectos a considerar en el intento de asociar un determinado nombre de lugar a una especie, ya que se puede caer en equivocaciones si no se conoce bien la etnotaxonomía o la flora del territorio.

\section{CONCLUSIONES}

Como ya se ha afirmado (Sanz Elorza 2006; Villar 2005), el análisis de los topónimos de origen vegetal puede servir para estudiar y manifestar la etnodiversidad de un territorio dado, englobando tanto diversidad biológica como diversidad cultural. Se pone de manifiesto en este trabajo la importancia de estudios etnobotánicos para la ampliación del conocimiento del vocabulario local y como herramienta para la comprensión de la cultura de 
un territorio, particularmente de la forma de interpretar el paisaje por las personas nativas del mismo y su manera de designar los lugares.

Se ha constatado que los estudios toponímicos pueden ser un buen complemento de los etnobotánicos, pudiendo aportarse información entre ambos y enriqueciendo con ello el acervo cultural local en lo referente al medio natural. Con los estudios etnobotánicos se documentan nuevos nombres vernáculos de la plantas y se potencia el conocimiento de ciertos recursos vegetales empleados tradicionalmente por la población, cuyo valor subjetivo en la cultura ha ido mermando en muchos casos con el tiempo y los nuevos modos de vida. Por otro lado, los estudios locales de toponimia, con atención a los fitotopónimos, nos indican el valor de ciertas especies en esa cultura, no solo como referencia geográfica, sino aportando, en ocasiones, información sobre los usos de las plantas, el manejo que el ser humano realiza de su entorno, o incluso proporcionando datos para descripciones de paisajes hoy día transformados.

Destacamos, en relación a esta información que muchos topónimos aportan acerca del lugar, la importancia de aquellos que derivan de nombres de plantas. Los fitotopónimos, que generalmente indican la presencia de cierta especie vegetal, pueden dar lugar a interpretaciones sobre la ecología del territorio, sobre todo si aluden a especies estenoicas. Asimismo, tienen importante valor en fitogeografía, tanto de época presente como para interpretar las distribuciones pasadas de ciertos grupos vegetales en paleofitogeografía, si se trata de taxones no presentes en ese lugar en la actualidad. Los sinfitónimos tienen un valor especial, ya que además son indicadores del tipo de paisaje existente o preexistente, pues son nombrados por la especie principal de una determinada unidad de paisaje, y en la mayoría de ellos coincidente con la especie principal de una determinada comunidad vegetal, que es reconocida popularmente.

Las especies que conjugan sus nombres vernáculos en la fitonimia local de este territorio son en su mayoría especies bien conocidas y empleadas para algún uso por los habitantes, como se ha comentado. El estudio de la toponimia local nos ha permitido constatar, en cierta medida, una pérdida de conocimiento asociado a las plantas que han sido empleadas tradicionalmente en el área. Esta aculturación viene dada por un lado por la pérdida de algunos vocablos empleados para nombrar plantas, como en los casos comentados, aportándose por tanto datos acerca de una posible erosión lingüística. Por otro lado, se ha constatado una pérdida de la información asociada al uso y manejo de las plantas, pese a que se siguen conociendo las mismas con los nombres vernáculos que, además, forman determinados topónimos en ese territorio, como prueba de su importancia pasada en la cultura local. 


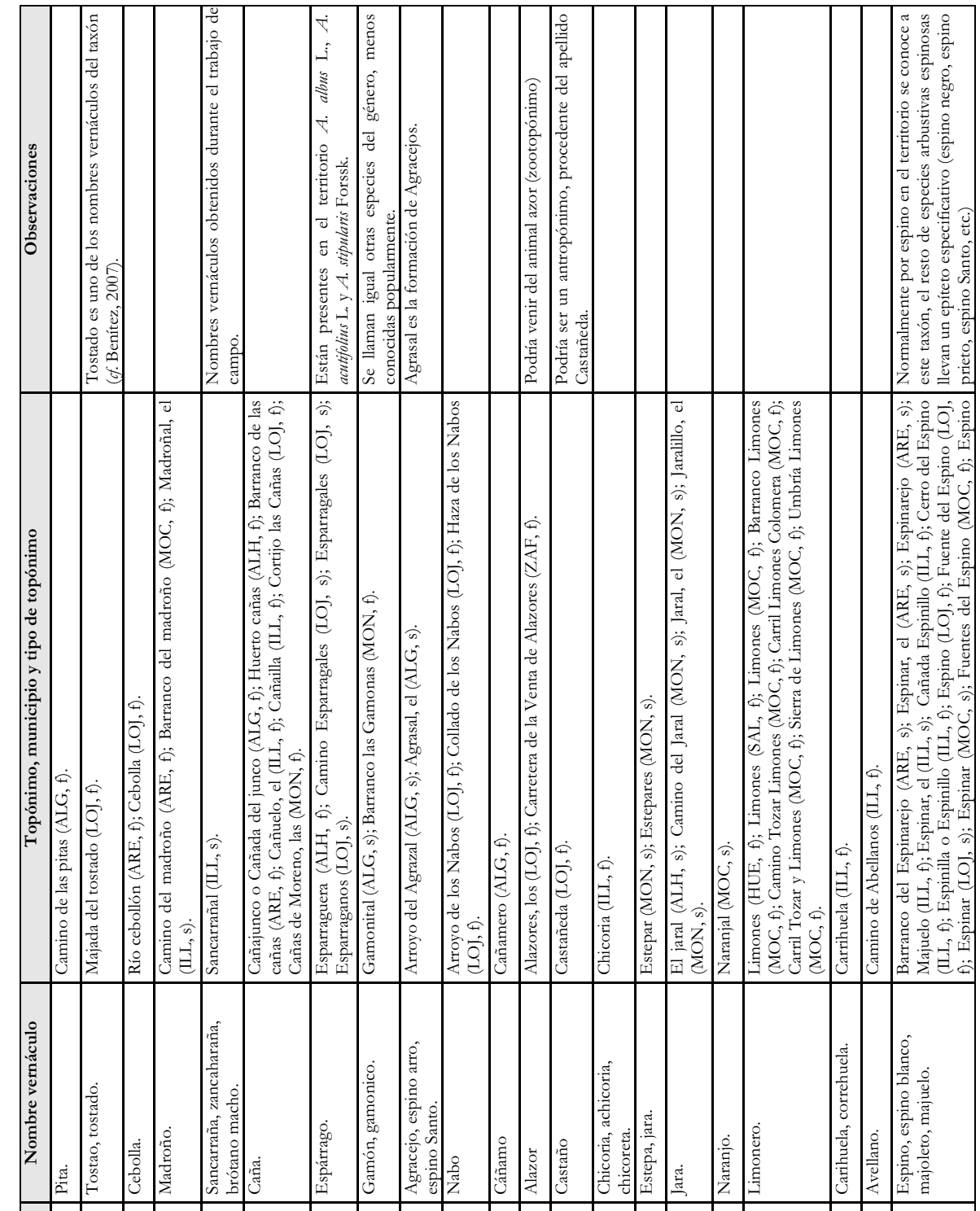

荛

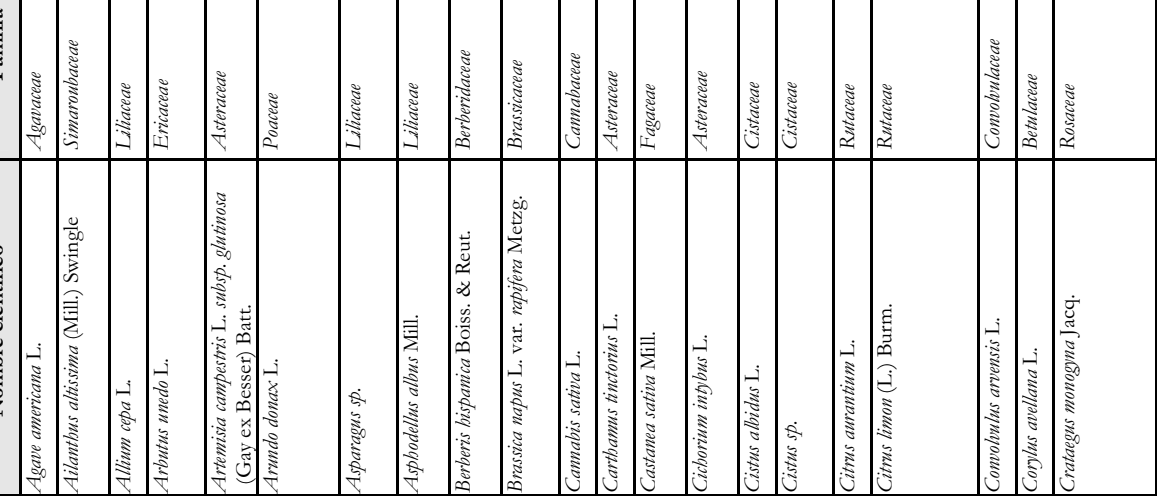




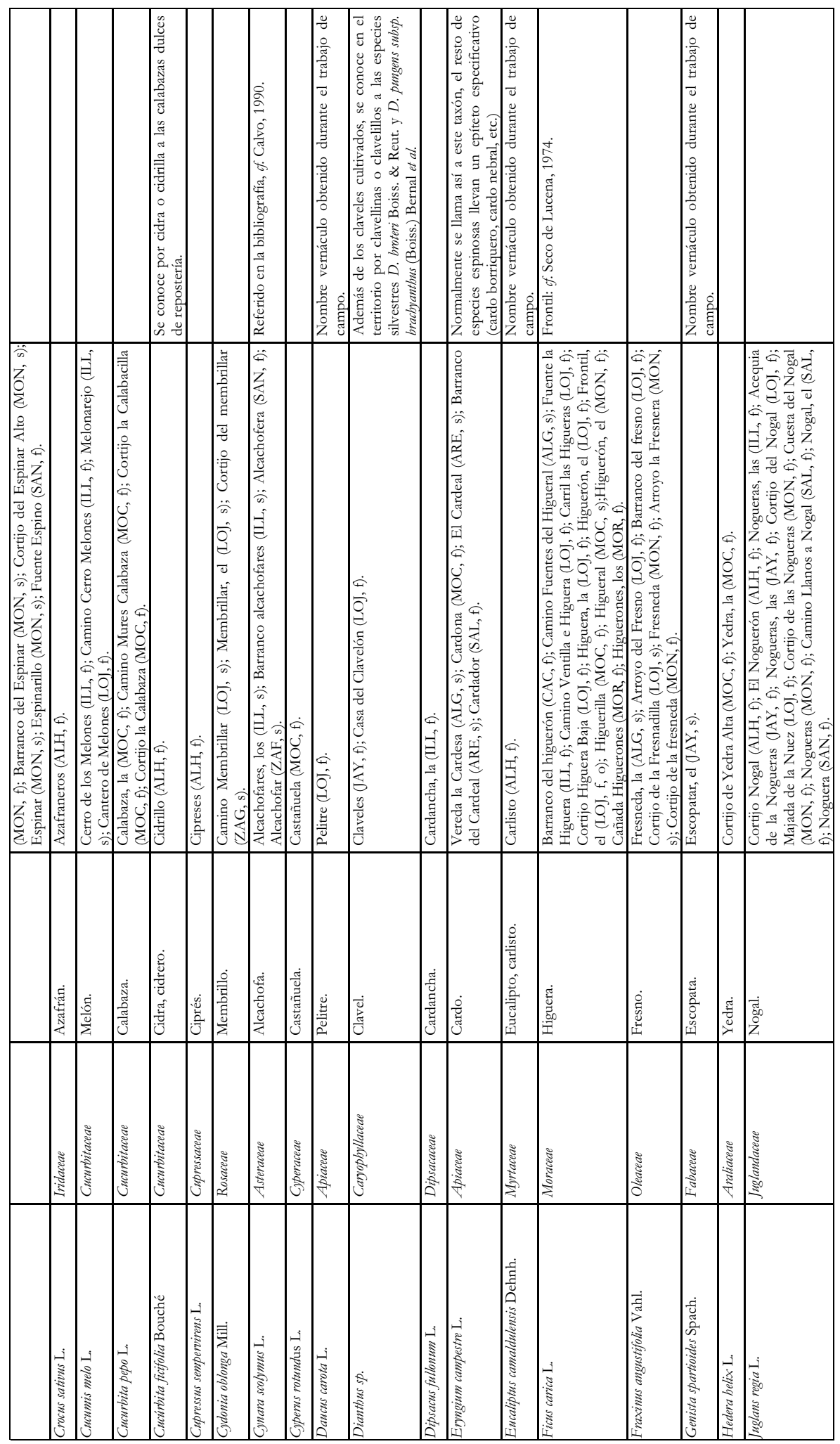




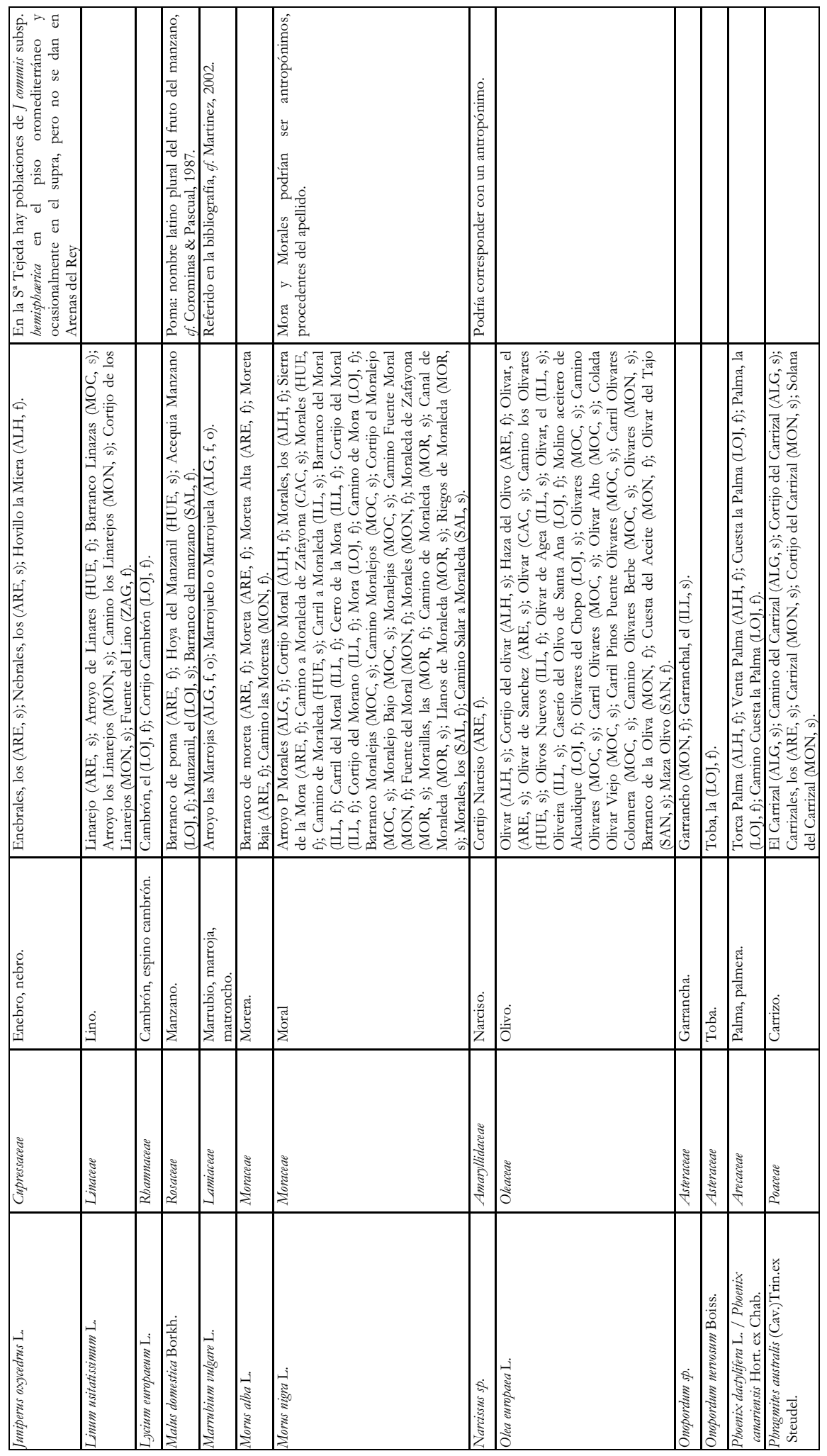




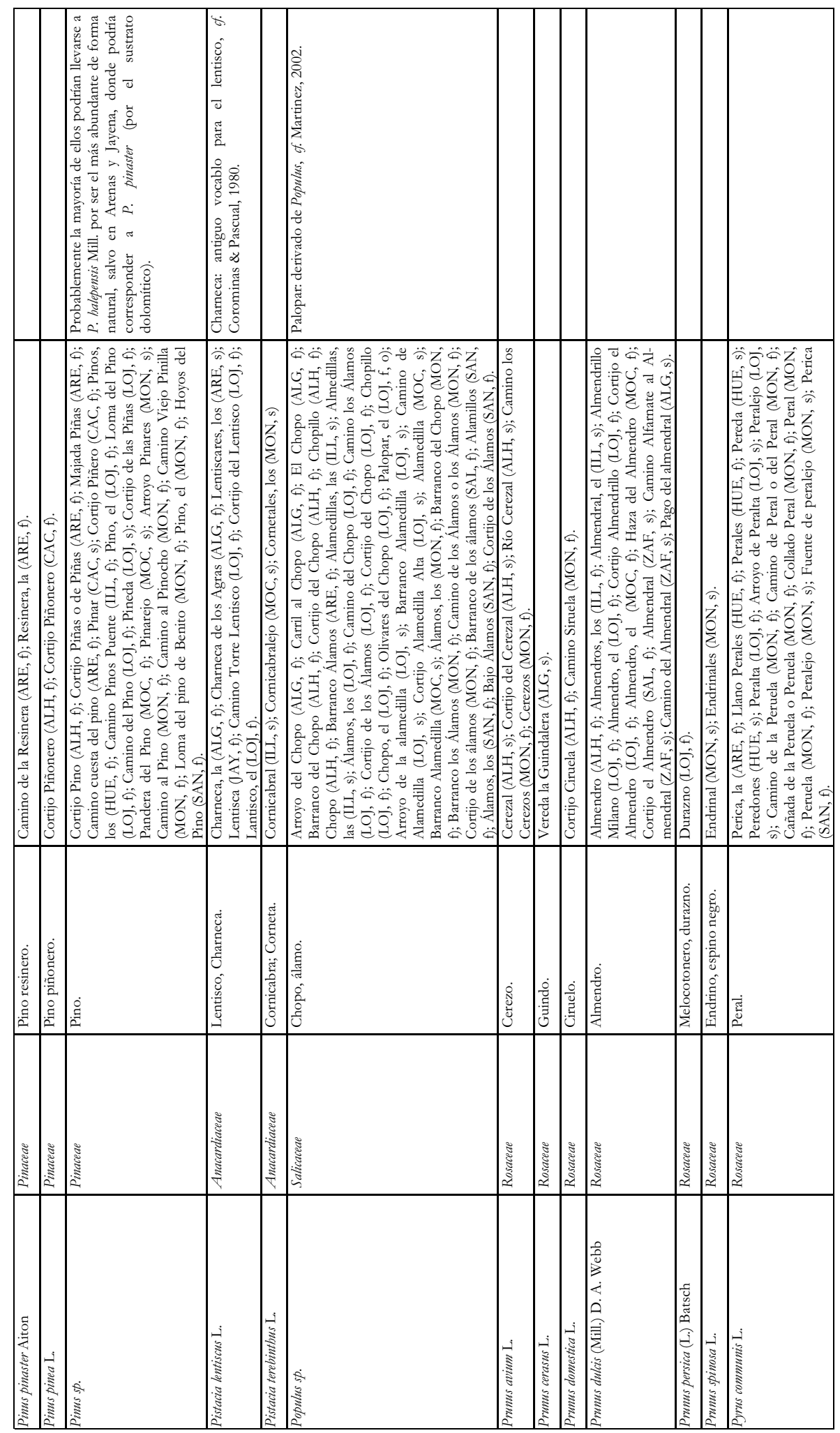




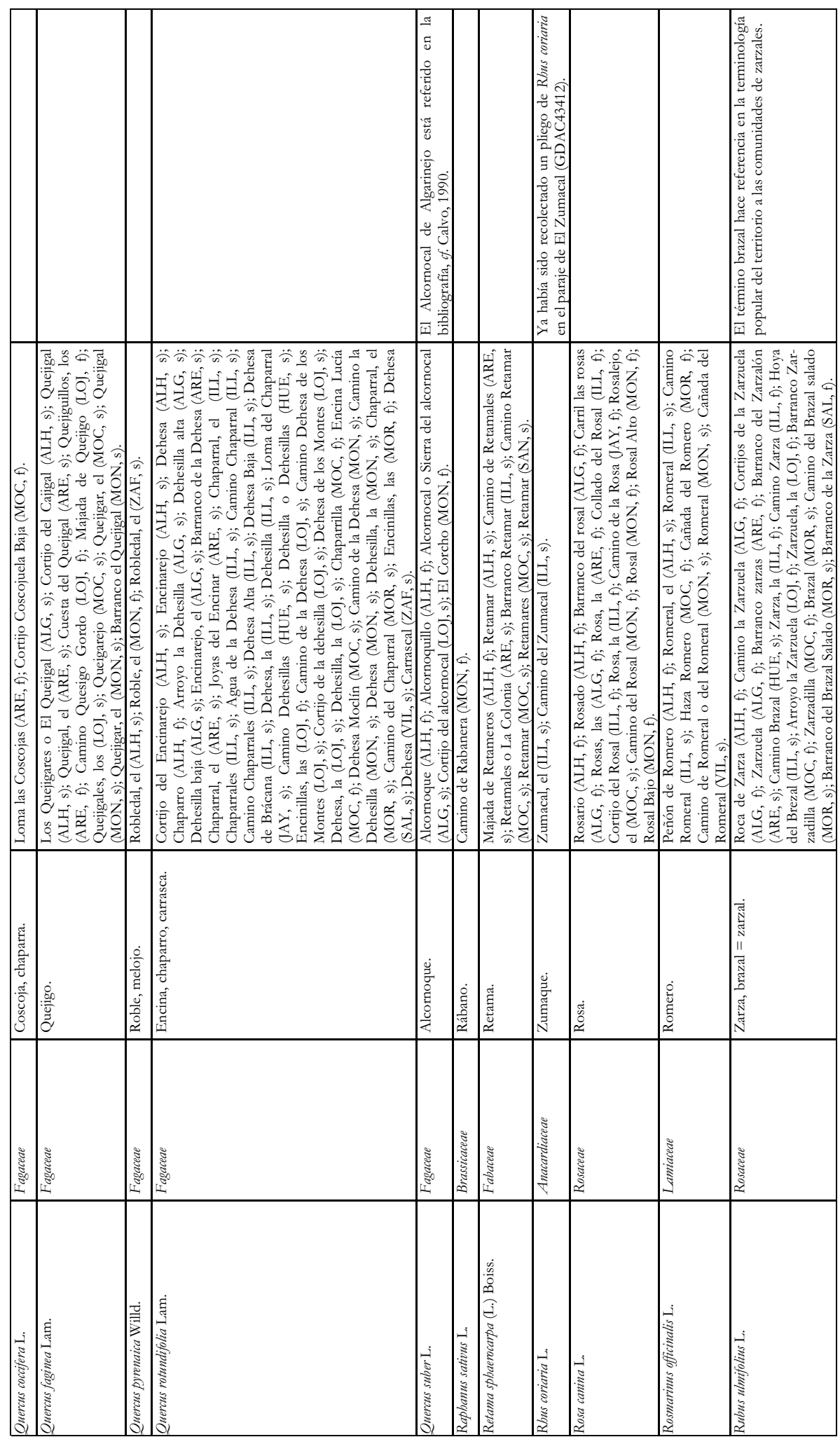




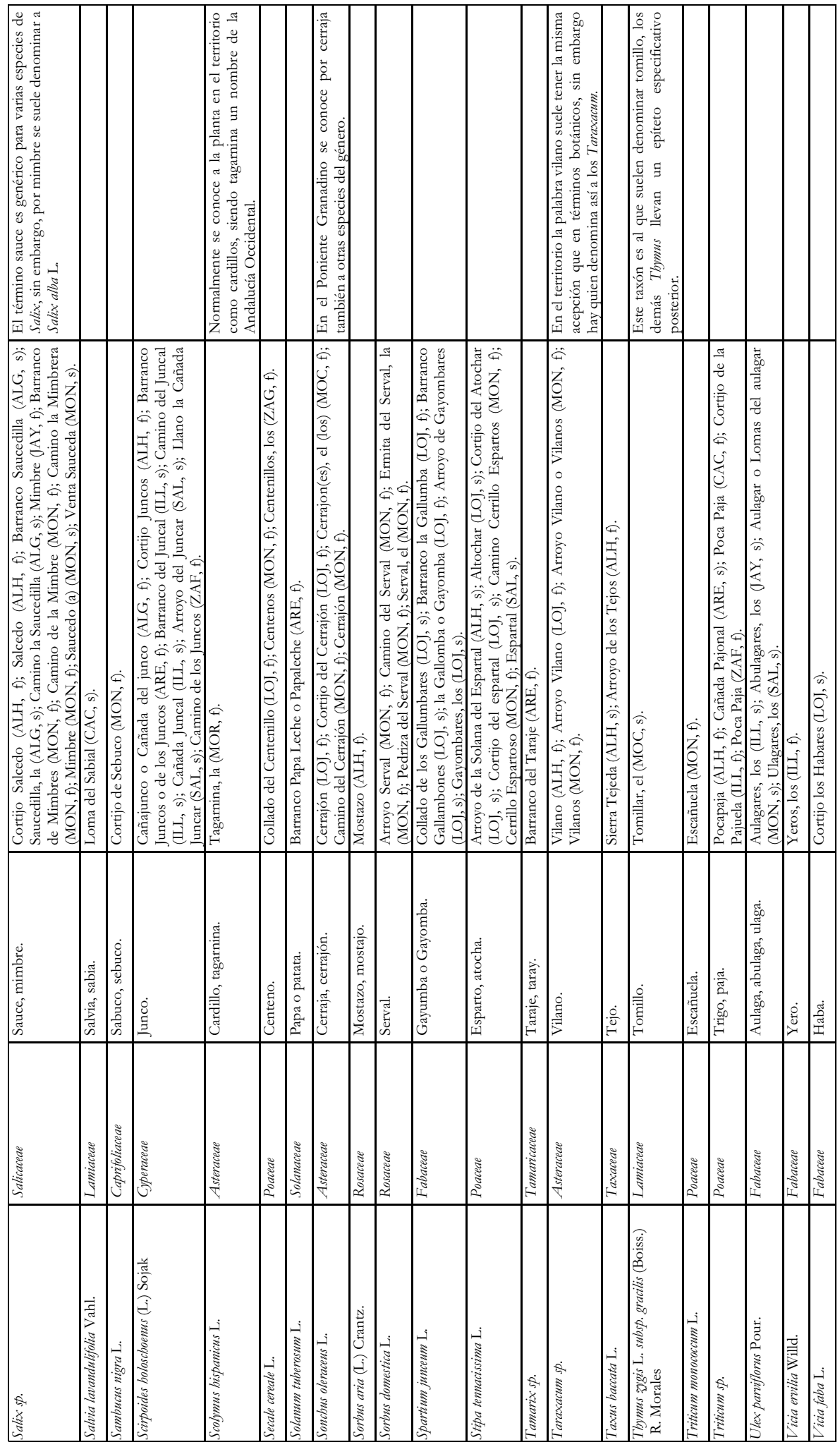




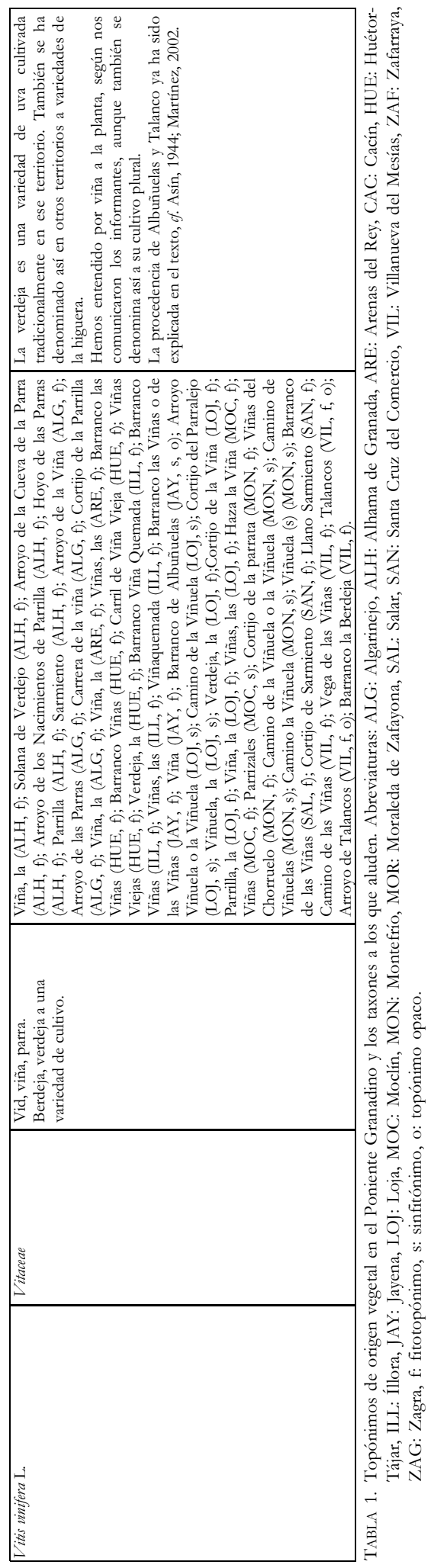




\section{BIBLIOGRAFÍA CITADA}

Asín Palacios, M. 1944. Contribución a la toponimia árabe de España. Granada: CSIC.

Barrau, J. 1976. "L'ethnobiologie", en R. Gresswell y M. Godelier, Outils d'enquéte anthropologique. 73-83. París: François Maspero.

Benítez Cruz, G. 2007. El uso de las plantas a través de la cultura popular lojeña. Una perspectiva etnobotánica. Granada: Fundación Ibn al-Jatib.

Benítez Cruz, G. 2009. Etnobotánica y etnobiología del Poniente Granadino. Tesis Doctoral Inédita. Universidad de Granada.

Boissier, P. É. 1839-1845. Voyage botanique dans le midi de l'Espagne... París, 2 vols.

Calvo Baeza, J. M. 1990. Nombres de lugar españoles de origen árabe. Pliegos de encuentro islamo-cristiano. Madrid: Darek-Nyumba, D.L.

Caro Baroja, J. 1991. Los pueblos de la península ibérica: temas de etnografía española. San Sebastián: Txertoa.

Ceballos Jiménez, A. 1998. Diccionario ilustrado de los nombres vernáculos de las plantas en España. Madrid: Ed. Andriala, S.L.

Cotton, C. 1996. Ethnobotany. Principles and Applications. Chichester, UK: Wiley \& Sons.

Corominas, J. y J. A. Pascual. 1980-1987. Diccionario crítico etimológico castellano e hispánico. Madrid: Gredos.

Fernández Pareja, F. 1982. Vocabulario de Priego de Córdoba y su comarca. Córdoba: Monografías de "Espiral".

Galeote, M. 1988. El habla rural del Treviño de Iznájar, Villanueva de Tapia y Venta de Santa Bárbara. Granada: Ayuntamiento de Iznájar.

González-Tejero García, M. R. 1989. Investigaciones etnobotánicas en la provincia de Granada. Tesis Doctoral. Universidad de Granada.

Instituto de Cartografía. 1990. Inventario de toponimia. Granada. Sevilla: Consejería de Obras Públicas y Transportes, Junta de Andalucía.

Laza Palacios, M. 1947. Estudios sobre la flora y la vegetación de las Sierras Tejeda y Almijara. Madrid.

Llorente Maldonado de Guevara, A. 1991. Los topónimos españoles y su significado. Salamanca: Universidad de Salamanca.

Marín Calderón, G. 1978. Estudio florístico y fitosociológico de la sierra de Loja. Tesis Doctoral. Universidad de Granada.

Martin, G. J. 2004. Ethnobotany. A methods manual. People and plants conservation series. WWF, Earthscan Publications.

Martínez Ruiz, J. 2002. El lenguaje del suelo (Toponimia). Jaén: Universidad de Jaén.

Moliner, M. 1983. Diccionario del Uso del Español. Madrid: Gredos, 2 vols.

Morales, R.; M. J. Macía; E. Dorda y A. García Villaraco. 1996. Nombres vulgares II. Madrid: CSIC. Archivos de Flora Ibérica, 7.

Morell y Terry, L. 1997 [1888]. Estudio sobre las causas de la decadencia de la agricultura en la provincia de granada y medios para regenerarla. Edición facsímil. Granada: Universidad de Granada.

Real Academia Española. 1995. Diccionario de la lengua española. Madrid: Espasa Calpe. Rodríguez Titos, J. 1996. El habla de los Montes Orientales. Granada: Gráficas Lino.

Ruiz de la Torre, L. 1988. Sinfitónimos, en L. Villar (ed.), Homenaje a Pedro Monserrat: 1027-1031. Huesca y Jaca: IEA e IPE-CSIC. 
Salas Pascual, M. y M. T. Cáceres Lorenzo. 2000. "Datos históricos de la presencia de fitónimos relacionados con el género Quercus L. en Canarias". Vegueta 5: 341-347.

Sanz Elorza, M. y F. González Bueno. 2006. "Toponimia de origen vegetal en la provincia de Segovia y su sentido ecológico y etnobotánico". Lazaroa 27: 103-125.

Seco de Lucena Paredes, L. 1974. Topónimos árabes identificados. Granada: Universidad de Granada.

Torres Montes, F. 2004. Nombres y usos tradicionales de las plantas silvestres en Almería (estudio lingüistico y etnográfico). Almería: Diputación de Almería e Instituto de Estudios Almerienses.

Villar Pérez, L. 2003. Los saberes científico y popular en torno a las plantas del Pirineo Aragonés. Un ejemplo de diversidad cultural. Zaragoza: Monografías Real Acad. Cien. Fis. Quim. y Nat. Zaragoza, no 23.

Villar Pérez, L. 2005. "Toponimia de origen vegetal en el Alto Aragón, II. Sinfitotopónimos relacionados con arbustos y su sentido ecológico". Flora Montiberica 29: 43-53.

Fecha de recepción: 28 de octubre de 2008

Fecha de aceptación: 18 de mayo de 2009 